\title{
Incorporation of ice sheet models into an Earth system model: Focus on methodology of coupling
}

\author{
Oleg Rybak $^{1,2, *} *_{\oplus}$, Evgeny Volodin ${ }^{1}$, Polina Morozova $^{1,3}$ and Artiom Nevecherja ${ }^{1,4}$ \\ ${ }^{1}$ Institute of Numerical Mathematics of RAS, 8 Gubkina Str., Moscow 119333, Russia. \\ ${ }^{2}$ Sochi Research Center, RAS, 8 a Theatralnaya Str., Sochi 354000, Russia. \\ ${ }^{3}$ Institute of Geography of RAS, 37 Vavilova Str., Moscow 117312, Russia. \\ ${ }^{4}$ Kuban State University, 149 Stavropolskaya Str., Krasnodar 354040, Russia. \\ *Corresponding author.e-mail: Oleg@Rybak.vub.be
}

MS received 14 December 2016; revised 31 May 2017; accepted 1 August 2017; published online 6 March 2018

Elaboration of a modern Earth system model (ESM) requires incorporation of ice sheet dynamics. Coupling of an ice sheet model (ICM) to an AOGCM is complicated by essential differences in spatial and temporal scales of cryospheric, atmospheric and oceanic components. To overcome this difficulty, we apply two different approaches for the incorporation of ice sheets into an ESM. Coupling of the Antarctic ice sheet model (AISM) to the AOGCM is accomplished via using procedures of resampling, interpolation and assigning to the AISM grid points annually averaged meanings of air surface temperature and precipitation fields generated by the AOGCM. Surface melting, which takes place mainly on the margins of the Antarctic peninsula and on ice shelves fringing the continent, is currently ignored. AISM returns anomalies of surface topography back to the AOGCM. To couple the Greenland ice sheet model (GrISM) to the AOGCM, we use a simple buffer energy- and water-balance model (EWBM-G) to account for orographically-driven precipitation and other sub-grid AOGCM-generated quantities. The output of the EWBM-G consists of surface mass balance and air surface temperature to force the GrISM, and freshwater run-off to force thermohaline circulation in the oceanic block of the AOGCM. Because of a rather complex coupling procedure of GrIS compared to AIS, the paper mostly focuses on Greenland.

Keywords. Earth system model; Greenland; Antarctica; ice sheet; climate dynamics; surface mass balance.

\section{Introduction}

Studying the past climate changes and making projections into remote future by modelling methods is hardly possible without incorporation of ice sheets into mathematical models of the climate system. This issue was well understood decades ago. The first attempt to link a general circulation model (GCM) with ice sheets was perhaps made by Gates (1976). In this pioneering study, he employed a two-layer GCM with ice sheets just imposing specific ice-age boundary conditions corresponding to 18,000 years before present (kyr BP). Adem (1981a, b) studied the Last Glacial Maximum climate with a rather simple thermodynamic model using the similar approach, i.e., by introducing ice-age surface boundary conditions for the atmosphere dynamics equations. His thermodynamic climate model (Adem 1964, 1979) could be thought of as a kind of a prefiguration of what was 
later called 'models of intermediate complexity' (MICs). Though in Adem (1981a, b), ice sheets were accepted as 'passive' components of the Earth system, his studies constituted the basis for modern simulations with fully coupled Earth system models (ESMs). Ice sheet models (ISMs) at that time were at the stage of principal formulation and testing of numerical methods (e.g., Mahaffy 1976; Jenssen 1977) and more than one decade was required to develop a real dynamic ice sheet model (e.g., Huybrechts 1992).

One of the first real couplings of a GCM and an ISM was carried out by Gallée et al. (1992). They asynchronously coupled a simplified model of the three main Northern Hemisphere ice sheets and their underlying bedrock to a 2-D climate model, which linked together the atmosphere, ocean mixed layer, sea ice, and continents. Further on, the Louvain-la-Neuve climate model (LLN 2-D model) has been extensively used to simulate the Northern Hemisphere ice volume under both the insolation and $\mathrm{CO}_{2}$ forcing (Berger et al. 1998).

Impressive improvement of computing facilities gave start to development of ESMs. In the ESMs, processes in all planetary subsystems are supposed to be dynamically coupled. ESMs performance has strikingly evolved during the last decade. Still, elaboration of a fully coupled ESM remains a tantalizing challenge for model developers because of the dramatic difference in spatial and temporal scales for integration of the atmospheric and oceanic parts on the one hand, and ice-sheet part on the other. Characteristic spatial resolution of a GCM is equivalent to $100-500 \mathrm{~km}$ (in case of an MIC is even lower). Approximately, this is one order of magnitude higher than that of an ice sheet model, ICM $(5-40 \mathrm{~km})$. The difference in integration time steps is even bigger (minutes for GCMs and from a month to 1 year for ICMs).

Several methodological approaches exist for temporal and spatial coupling of AOGCMs (or MICs) and ICMs (Vizcaíno et al. 2008, 2010; Robinson et al. 2010; Fyke et al. 2011; Roche et al. 2014; Thoma et al. 2015). Reviewing them is out of scope for this paper. We focus on the description of our own approach used to couple the climate model of the Institute of Numerical Mathematics of RAS, INMCM, and ice sheet models of the Greenland and the Antarctic ice sheets (GrISM and AISM, respectively). INMCM can be considered as a prototype of an ESM, because besides ocean and climate dynamics, it includes biogeochemical cycle in the ocean, land hydrology, etc. The obvious shortcoming of the INMCM was the lack of dynamically coupled evolving ice sheets. To fill this gap, we elaborated an approach aiming at coupling of the GrISM and AISM (modified versions of the models described by Huybrechts and Wolde 1999 and Huybrechts 2002) to INMCM by means of a relatively simple buffer model. The latter serves a mediator for assimilation of INMCM-generated low resolution climate fields to high resolution domains enclosing Antarctica and Greenland. On the earlier stage of the research reported in Rybak and Volodin (2015), we formulated basic algorithms of a buffer model for the Greenland ice sheet and collated model generated fields of surface air temperature to direct measurements on the automatic weather stations (AMS) and reconstructions. Later, Rybak et al. (2016) presented the way of calculating surface mass balance in a buffer model. In this paper, we proceed with previous research and expand the study on Antarctica. We do not consider response of the GrISM and AISM on modelled climate forcing and concentrate mainly on the procedure of coupling. Its strategy is considered in section 2. Because of certain fundamental distinctions between GrIS and AIS, two substantially different coupling approaches are implemented. While direct transfer of the INMCM-generated surface temperature and precipitation anomalies to AISM is used, a buffer energy- and water-balance model (EWBM-G) is applied to accurately calculate daily air surface temperature and precipitation (section 3). Numerical experiments are carried out to validate calculation of GrIS' surface mass balance (SMB) components (section 4). Summary and further work are presented in section 5 .

\section{Architecture of the ESM and formulation of the coupling strategy}

The ESM consists of four main mega-blocks. Each of the mega-blocks has its own block architecture, which in a simplified way is indicated in figure 1. Mega-block 'INMCM' (or, conventionally, 'climatic' mega-block) consists of blocks responsible for the ocean and atmosphere dynamics. Spatial resolution is $4^{\circ}$ (latitude) $\times 5^{\circ}$ (longitude) in the atmospheric block and $1.5^{\circ}$ (latitude) $\times 2^{\circ}$ (longitude) in the oceanic block. It should be kept in mind that the structure of the 'climatic' mega-block is much more complicated than what is shown in figure 1. It also includes blocks for sea ice, oceanic biogeochemistry, stratosphere and 


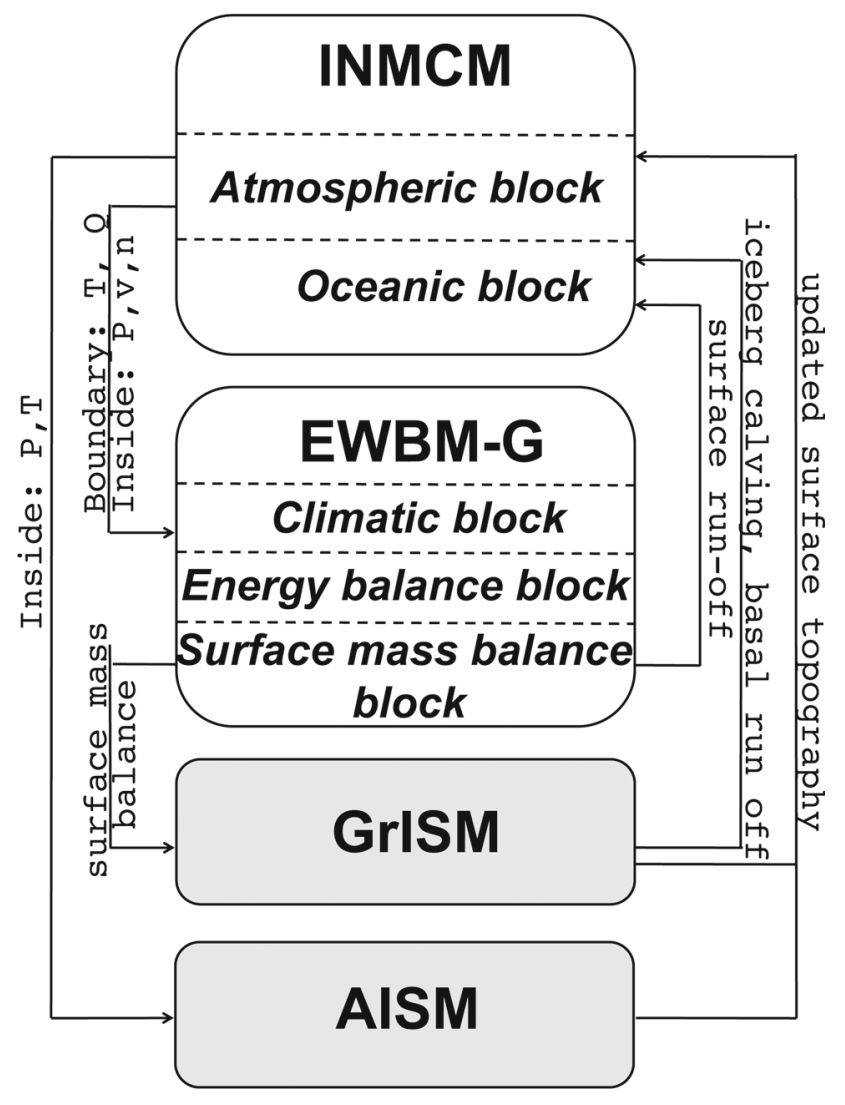

Figure 1. ESM architecture.

thermosphere dynamics, land hydrology, etc. (For further details of the 'climatic' mega-block structure and for description of component blocks, see Volodin et al. 2010, 2016; Volodin 2013 and references therein.) Skill of the INMCM was verified in reproduction of the modern climate (Volodin et al. 2010, 2013). INMCM has been widely used during recent years for studying interactions and feedbacks within the Earth's climate system; for instance, for elucidation of roles of greenhouse gases (Volodin 2014, 2015), vegetation (Yurova and Volodin 2011) and aerosoles (Volodin and Kostrykin 2016).

Response times in the 'climatic' mega-block (subsystem) and in the ice-sheet subsystem (megablocs GrISM and AISM) of an ESM differ dramatically. It naturally leads to separation of time scales in corresponding sub-models, which makes it possible to couple them iteratively within the ESM. It means that at the first stage the atmosphere-ocean sub-model is run with given ice-sheet boundary conditions. At this stage, ice sheets are considered unchanged, and evolving model 'climate' is equilibrated with them. At the subsequent stage, sub-models alternate and equilibrated climate is considered unchanged prescribing forcing for ice sheets. The latter are not necessary to be equilibrated with climate because of huge inertia. Contemporary computer performance establishes certain restrictions on the experimental set-up and leads to following modes of coupling (Barbi et al. 2014):

- Synchronous coupling is applicable for relatively short numerical experiments. Atmosphere-ocean and ice sheet sub-models alternate after certain fixed period of integration, say, one year. In case seasonal variations in ice sheet dynamics are neglected, this period corresponds to one time step in integration of an ice-sheet sub-model. After this step is completed, changes in ice geometry and freshwater fluxes are transferred back to the atmosphere-ocean sub-model. The point is that in the synchronous mode, the sub-models do not reach equilibrium at each time step.

- Asynchronous coupling is normally used for the numerical experiments of rather long duration to study slow evolving ice sheets. In this mode, ice sheets are integrated for the period, say, 1000 years with prescribed atmosphereocean boundary conditions, and after alternation, atmosphere-ocean subsystem adapts to the new ice topography and freshwater fluxes during much smaller period of the order of model decades.

To couple the AISM and the GrISM to INMCM, we adhere two different strategies described below.

\subsection{Antarctica}

Coupling of the AIS to the INMCM is rather straightforward. Firstly, Antarctica is covered by the INMCM grid points less scaresly in the longitudinal direction compared to Greenland, especially close to the South Pole (figure 2). Secondly, standard AISM (e.g., model of Hyubrechts mentioned in Introduction) uses annual average surface air temperature and precipitation rate as a climatic input. Of course, seasonality in observed precipitation rate (Cazenave et al. 2000) as well. It is predicted in all surface mass balance components simulated by a regional climate model (Lenaerts et al. 2012). But this factor has only minor effect on the computation of annual SMB.

Obvious lack of meteorological observations in Antarctica compared to Greenland makes air temperature reconstructions less reliable. Comparison of the INMCM-generated air temperature field 

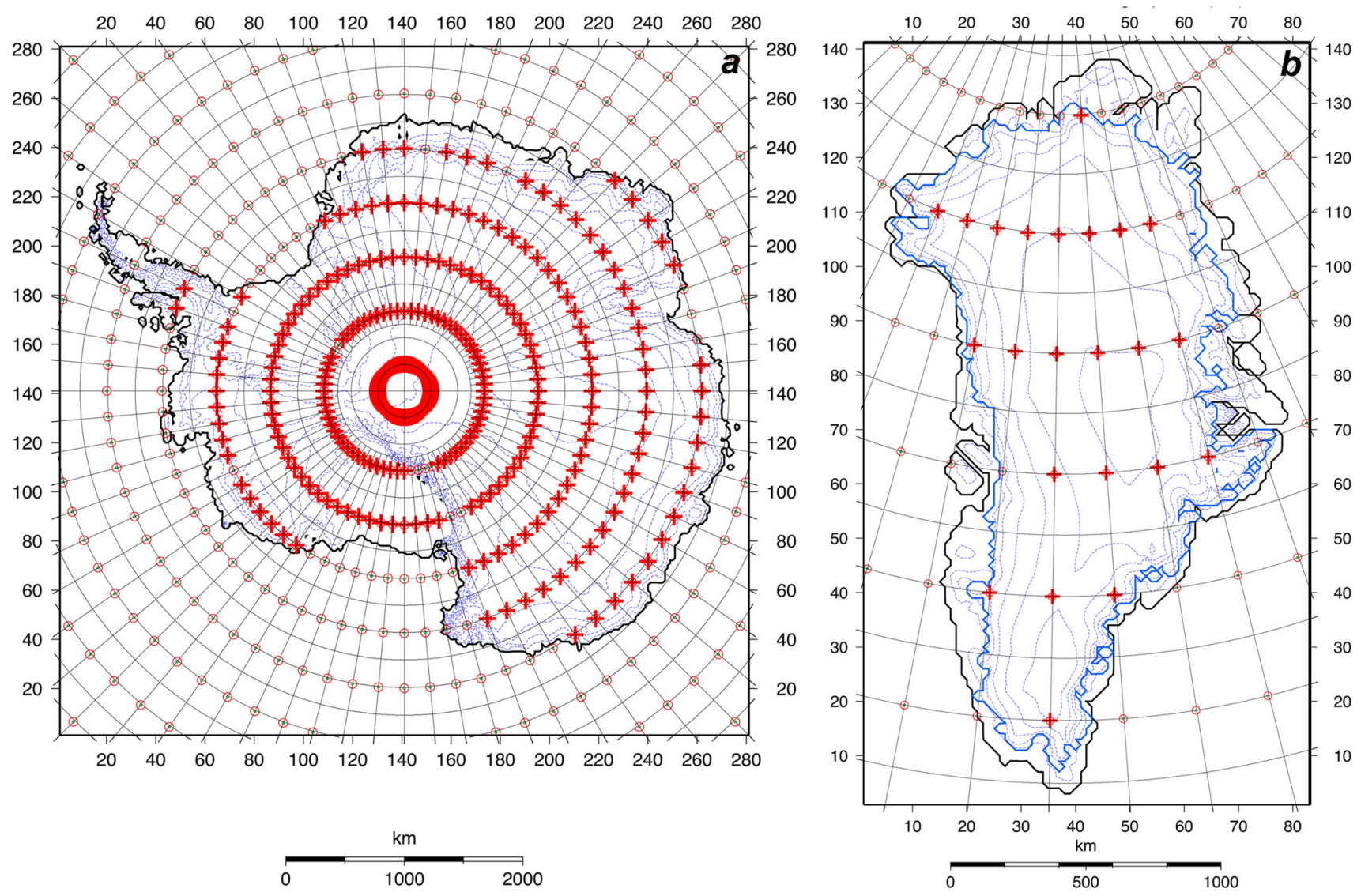

Figure 2. Spatial grid $5^{\circ} \times 4^{\circ}$ employed by the INMCM superimposed on the standard $20 \times 20 \mathrm{~km}$ grid employed by (a) the Antarctic and (b) the Greenland ice sheet models. Shown in the background is the surface elevation (isolines every $500 \mathrm{~m}$ ). In this and following figures, side ticks numbering corresponds to the numbers of the gridpoints of $20 \times 20 \mathrm{~km}$ spatial grid.

with reconstruction of Huybrechts (1993) reveals no significant differences (figure 3 ). In contrast to GrIS, in this study, we neglect ablation in Antarctica. Hence, there is no need to calculate surface energy balance. Though ablation really happens in some coastal regions, especially on the coast of the Antarctic peninsula and on ice shelves fringing Antarctica (van de Berg et al. 2005), for the rest of the continent, it may not be taken into account (at least until ice dynamic on the margins is not the focus of the research). Assumed absence of ablation makes AISM less sensitive to the surface air temperature precision. Inconsistencies in modelled and reconstructed air surface temperature are not really essential. Surface temperature is used as an upper boundary condition for the calculation of a 3-D temperature field in the body of an ice sheet. It affects ice sheet dynamics via thermomechanical coupling - warmer ice deforms easier. Systematic temperature deviations are easily mitigated by tuning parameters in respective expressions parameterizing ice rheology. What is really important is temperature anomalies caused by any external reason, which are prescribed by the INMCM. In these circumstances, we found it reasonable to directly impose INMCM-generated air surface temperature as an upper boundary condition for ice temperature calculation in the AISM.

Imposing precipitation is more complicated. Though the INMCM overestimates annual precipitation rates over Antarctica, approximately by factor of two, it keeps its pattern (figure 4). Compared to Greenland, sublimation/deposition plays an essential role in Antarctic SMB. Neglecting sublimation/deposition would be perhaps more influential for surface mass balance than neglecting ablation. van de Berg et al. (2005) estimated fraction of deposition in the vast areas of East Antarctica as high as $10-20 \%$ of total solid precipitation. Characteristic sublimation in the marginal areas also reaches $10-20 \%$, but in the areas with steep slopes (e.g., Transantarctic Mountains) may exceed $50 \%$. Again, as in case with air surface 
$\simeq$

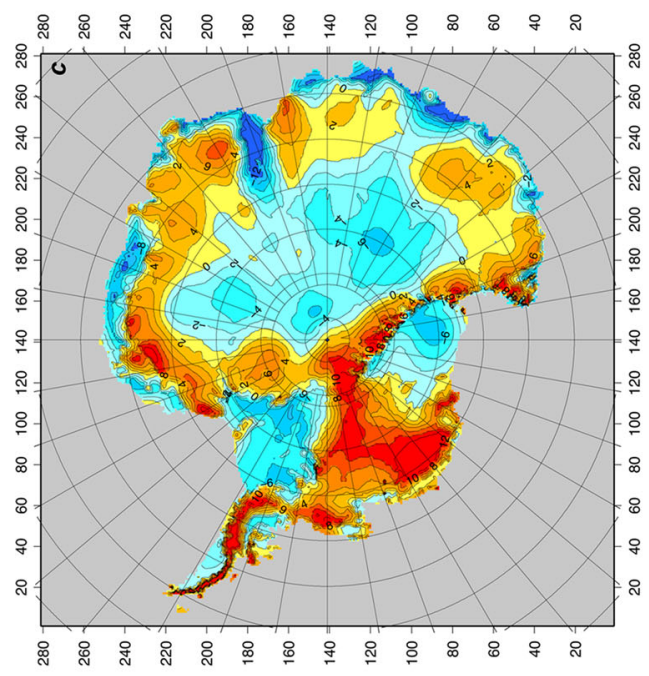

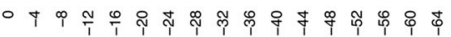
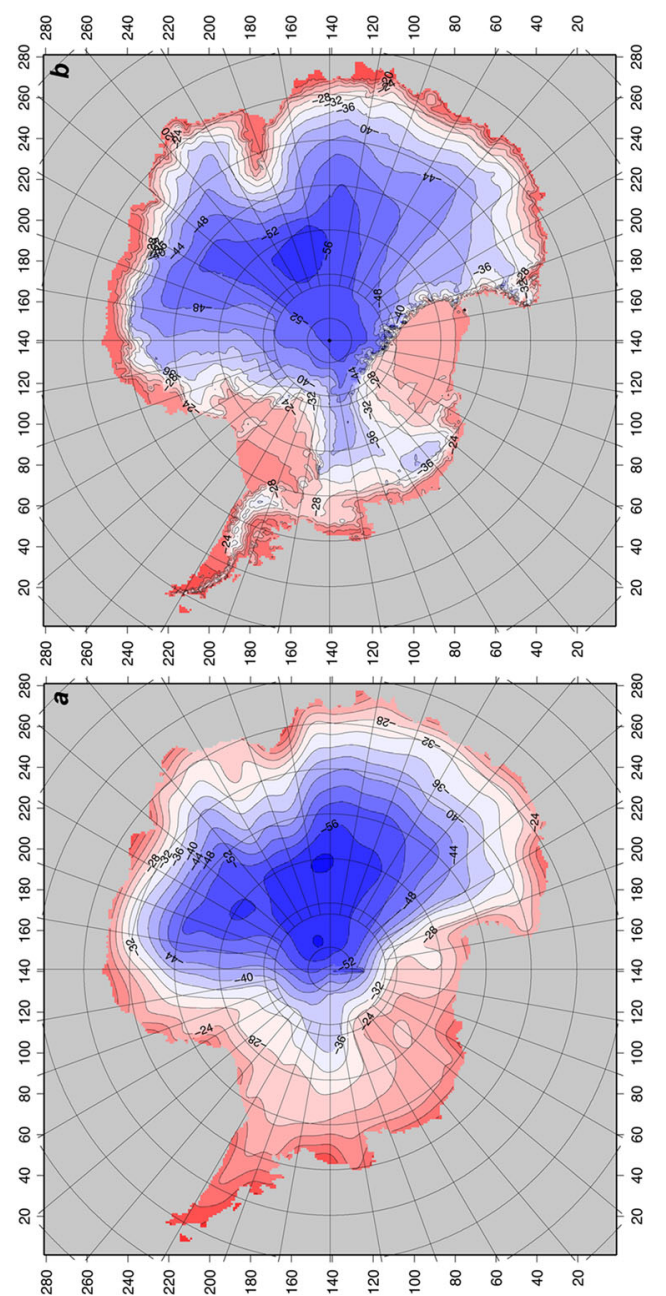

芯

$\left.\right|_{\frac{2}{2}}$

.

2

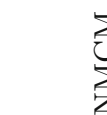

至

(2)

영

I

हो ฮ

1.
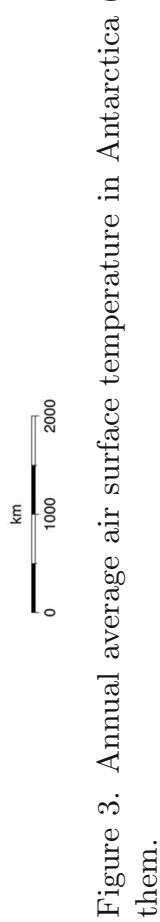

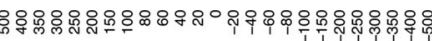
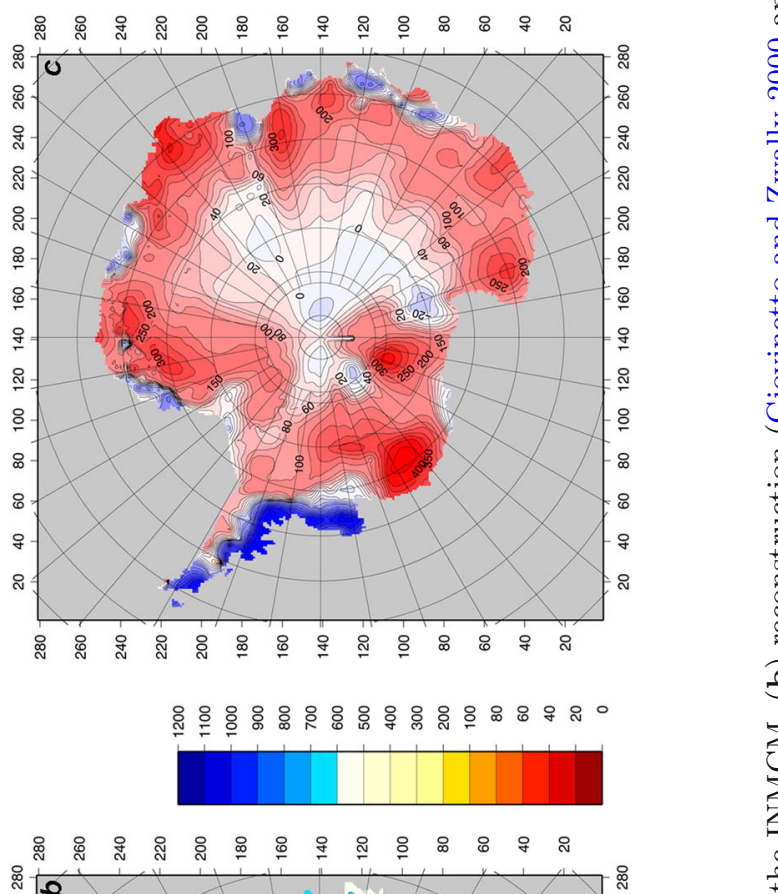

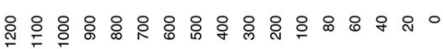
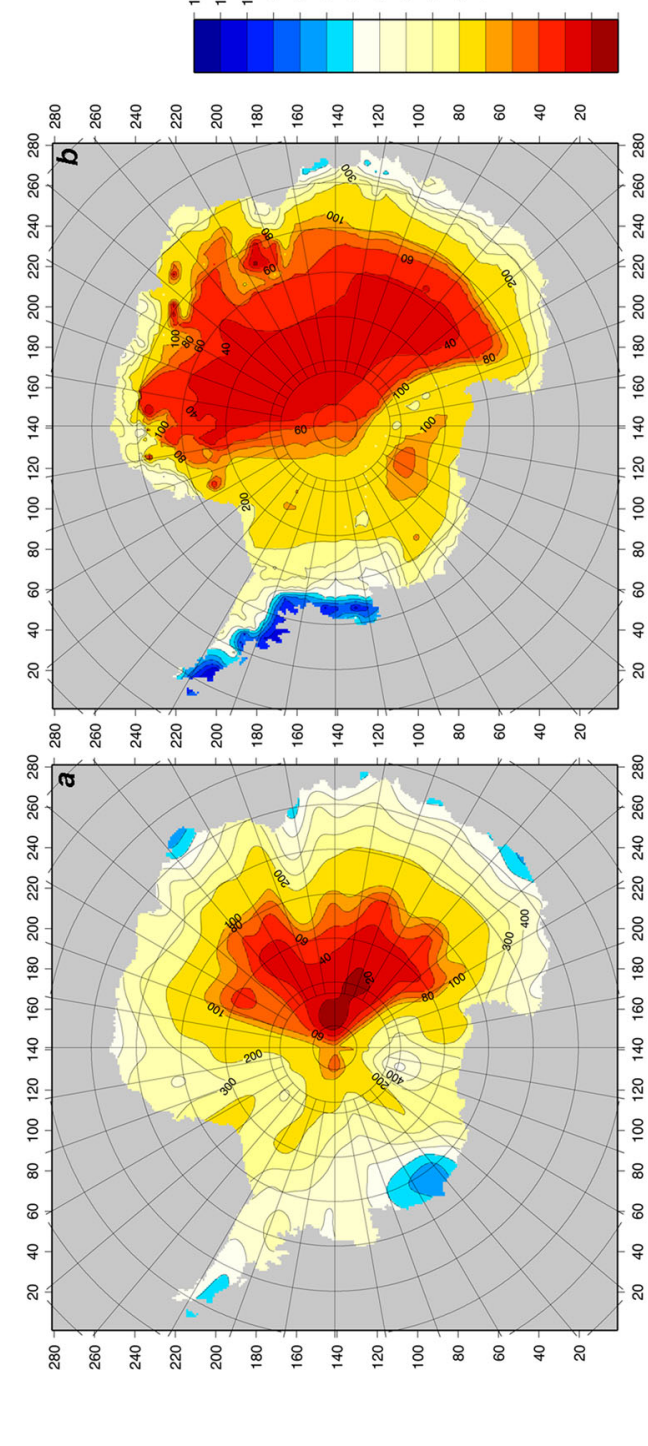

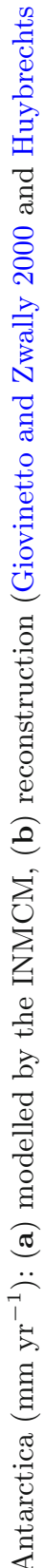

.$\nexists$

荡

究

.

离

㝵

过

80

เข

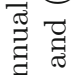

安官

मㅇㅇㅇ

${ }_{0}^{0}$ व 
temperature, there are not enough reliable controls on sublimation/deposition because the net of weather stations in the interior of Antarctica is dramatically sparse. At the current stage of the research, we find it expedient to deal with anomalies generated by the INMCM, i.e., differences between precipitation in the given year and a chosen conventional INMCM 'climatic' mean. Anomalies are further imposed on the reconstructed accumulation rate field. In our study, we use reconstruction of Huybrechts et al. (2000), which in turn, is based on the Giovinetto and Zwally (2000) accumulation map. Of course, in the context of the current study, with the pre-industrial climate, anomalies are essentially low. It will not be the case in the experiments with future climate or palaeo-climates.

\subsection{Greenland}

Direct downscaling (e.g., by statistical method) of INMCM-generated 'climate' to GrISM is not effective because of several reasons considered by Rybak and Volodin (2015). Instead, we use a simple buffer model - an Energy and Water Balance Model for Greenland (EWBM-G). It was specially designed as a mean of dynamic downscaling. At the moment, to test efficiency of the EWBM-G, we consider only one-way coupling of the GrISM to the AOGCM, i.e., without feed-back of the changing ice sheet topography and run-off on the atmospheric and the oceanic blocks of the INMCM. In this reduced coupling mode, daily output of five climatic variables (air surface temperature, surface specific humidity, surface wind speed, sea-level air pressure, and total cloudiness) generated by the INMCM are interpolated from 'climate' mega-block grid (see above) to the GrISM grid $20 \times 20 \mathrm{~km}$ (figure 2). Bi-cubic splines are used as an interpolation method.

\section{EWBM-G}

From the conceptual point of view, EWBM-G can be considered as a logical continuation and development of ideas and approaches elaborated earlier (Budyko 1969; Adem 1981a, b; North et al. 1981; Dobrovolski and Rybak 1992; Rybak 1992; Fanning and Weaver 1996; Petoukhov et al. 2000; Robinson et al. 2010). The model presented in this paper is the development of the version described by Rybak and Volodin (2015) and Rybak et al. (2016).
Similarly to the model REMBO (Robinson et al. 2010), EWBM-G was formulated for much more limited spatial area. The fundamental difference between REMBO and EWBM-G is that the REMBO was developed as a buffer between the ice sheet model and the climatic MIC CLIMBER2 (Petoukhov et al. 2000), which had much lower spatial resolution compared to INMCM (51 ${ }^{\circ}$ longitude $\times 10^{\circ}$ latitude). Thus, keeping the general approach implemented in REMBO, we developed our own model, which takes into account pitfalls of REMBO. We have also taken into account the experience of application of a regional climate model RACMO2/GR for the simulation of modern climate of Greenland (Ettema et al. 2010a, b). Spatial resolution of RACMO2/GR is $11 \mathrm{~km}$. This is quite enough for coupling of a climate model with an ice sheet model and to take into account small-scale effects (e.g., influence of relief on precipitation rate). Nevertheless, RACMO2/GR is overcomplicated for our purpose since it requires small temporal resolution comparable to that of a GCM (6 min). Therefore, essential computational cost makes it hardly applicable for long numerical experiments.

EWBM-G consists of three main blocks: climatic block, energy balance block and surface mass balance block (figure 1). The list of variables, except those explicitly explained in the text, and constants of the EWBM-G is given in table 1. Since exhaustive description of the EWBM-G can be found in Rybak and Volodin (2015) and Rybak et al. (2016), in the following sections, we provide only details necessary to understand the essence of the experimental studies.

\subsection{Climatic block}

Climatic block (CB) of the EWBM-G must not be confused with the 'climatic' mega-block of the INMCM. Two diffusion equations constitute the basis of the $\mathrm{CB}$ - for heat and water vapour, both formulated for unit atmospheric columns:

$$
\begin{aligned}
c_{p a} \rho_{a} h_{a} \frac{\partial T_{S L}}{\partial t}= & \nabla^{2}\left(D_{T} T_{S L}\right) \\
& +\left(1-\alpha_{p}\right) S-\left(A+B T_{A}\right) \\
& +L_{w} P_{w}+\left(L_{w}+L_{S}\right) M_{S} \\
\rho_{a} h_{e} \frac{\partial Q}{\partial t}= & \nabla^{2}\left(D_{q} Q\right)-P .
\end{aligned}
$$

The second term on the right side of equation (1) is responsible for absorbed solar radiation, the 
Table 1. List of variables in EWBM-G.

\begin{tabular}{|c|c|c|c|}
\hline Definition & Unit & Name & Value \\
\hline \multicolumn{4}{|l|}{ Variables } \\
\hline$D_{T}$ & $\mathrm{~W} \mathrm{~K} \mathrm{~K}^{-1}$ & Large-scale heat diffusion coefficient & \\
\hline$D_{Q}$ & $\mathrm{~kg} \mathrm{~s}^{-1}$ & Large-scale water diffusion coefficient & \\
\hline$n$ & - & Total cloudiness (in figure 1) & \\
\hline$p$ & $\mathrm{~N} \mathrm{~m}^{-2}$ & Atmospheric pressure (in figure 1) & \\
\hline$P$ & $\mathrm{~kg} \mathrm{M} \mathrm{M}^{-2} \mathrm{~s}^{-1}$ & Precipitation rate & \\
\hline$Q$ & - & Specific humidity of the surface air & \\
\hline$S$ & $\mathrm{~W} \mathrm{~m}{ }^{-2}$ & Surface insolation & \\
\hline$S U$ & $\mathrm{~kg} \mathrm{~m}^{-2}$ day $^{-1}$ & Daily sublimation amount & \\
\hline$S_{0}$ & $\mathrm{~W} \mathrm{~m}^{-2}$ & Insolation at the upper boundary of the atmosphere & \\
\hline$t$ & $\mathrm{~s}$ & Time & \\
\hline$T_{A}$ & $\mathrm{~K}$ & Surface air temperature & \\
\hline$T_{S L}$ & $\mathrm{~K}$ & Sea-level temperature & \\
\hline$v$ & $\mathrm{~m} \mathrm{~s}^{-1}$ & Surface wind velocity module (in figure 1 ) & \\
\hline$\alpha_{p}$ & - & Planetary albedo & \\
\hline$\varphi$ & $\mathrm{rad}$ & Geographical latitude & \\
\hline$\rho$ & $\mathrm{kg} \mathrm{m}{ }^{-3}$ & Air density & \\
\hline \multicolumn{4}{|c|}{ Parameters } \\
\hline$A$ & $\mathrm{~W} \mathrm{~m}^{-2}$ & Parameter in equation (1) & 222.3 \\
\hline$B$ & $\mathrm{~W} \mathrm{~K} \mathrm{~K}^{-1} \mathrm{~m}^{-2}$ & Parameter in equation (1) & 1.97 \\
\hline$c_{p a}$ & $\mathrm{~J} \mathrm{~kg}^{-1} \mathrm{~K}^{-1}$ & Air heat capacity & 1000 \\
\hline$H_{a}$ & $\mathrm{~m}$ & Conventional thickness of atmospheric layer & 8600 \\
\hline$H_{e}$ & $\mathrm{~m}$ & Conventional thickness of wet atmospheric layer & 2000 \\
\hline$L_{M}$ & $\mathrm{~J} \mathrm{~kg}^{-1}$ & Specific heat of fusion & $3.35 \times 10^{5}$ \\
\hline$\varepsilon$ & - & Parameter in equation (3) & 0.98 \\
\hline$\gamma$ & $\mathrm{K} \mathrm{km}^{-1}$ & Vertical lapse rate & See table 2 \\
\hline$\tilde{\gamma}$ & $\mathrm{K} \mathrm{m}^{-1}$ & Vertical lapse rate of free atmosphere & -0.007 \\
\hline$\sigma$ & $\mathrm{W} \mathrm{m}{ }^{-2} \mathrm{~K}^{-4}$ & Stefan-Boltzman constant & $5.67 \times 10^{-8}$ \\
\hline$\rho_{a}$ & $\mathrm{~kg} \mathrm{~m}^{-3}$ & Surface air density & 1.2754 \\
\hline
\end{tabular}

third term - for the long-wave energy balance, the fourth and the fifth - for latent heat of condensation and snow formation. Water vapour discharge in the right part of equation (2) is described by precipitation rate, which is parameterized according to Petoukhov et al. (2000) and Robinson et al. (2010). Daily mean surface air temperature $T_{A}$ is calculated using a spatially-uniform vertical lapse rate

$$
T_{A}=T_{S L}+\tilde{\gamma} z
$$

In the numerical experiments, we distinguish lapse rate in the free atmosphere $\tilde{\gamma}$ and instrumentally derived near-surface vertical lapse rate $\gamma$ used for surface mass balance (SMB) calculations.

\subsection{Energy balance block}

Energy balance on the surface of ice sheet $E$ is formulated for the so-called skin layer:

$$
\begin{aligned}
E= & S W_{\downarrow}(1-\alpha)-\varepsilon \sigma T_{S}^{4} \\
& +L W_{\downarrow}+S H F+L H F,
\end{aligned}
$$

where the first term on the right-hand side is absorbed solar radiation, the second one is surface emission of radiation, the third one - back emission of the atmosphere, the fourth - turbulent heat flux, and the fifth - latent heat flux. Surface temperature $T_{S}$ is assumed to be equal to air surface temperature $T_{A}$, but cannot exceed temperature of fusion

$$
\begin{array}{ll}
T_{S}=T_{A} & T_{A} \leq 273.15 \mathrm{~K} \\
T_{S}=273.15 K & T_{A}>273.15 \mathrm{~K} .
\end{array}
$$

$T_{A}$ is calculated in EWBM-G using boundary conditions generated by the INMCM. Hourly values of $T_{A}$ are defined as follows:

$$
T_{A}=\bar{T}_{A}-\tilde{T}_{A} \cos \left(2 \pi \frac{\hat{t}}{24}\right),
$$


where $\tilde{T}_{A}$ is the daily amplitude (tuned parameter), $\hat{t}=0, \ldots, 23$ - time in hours, and $\bar{T}_{A}$ is the daily average air surface temperature.

\subsection{Surface mass balance block}

Annual mass balance on the surface of GrIS (SMB) is the key variable linking the INMCM and the GrISM (figure 1). SMB is expressed as a difference between daily accumulation $A C$ in $\mathrm{kg} \mathrm{m}^{-2}$ day $^{-1}$ and daily run-off $R O$ (same units):

$$
\begin{aligned}
S M B= & \sum_{1}^{365} A C-R O=\sum_{1}^{365}[(P S+P L-S U) \\
& -(M-R F)] .
\end{aligned}
$$

Accumulation $A C$ consists of the sum of solid and liquid precipitation, $P S$ and $P L$, from which the amount of surface evaporation $S U$ is subtracted. Run-off consists of melted snow and ice $M$ and liquid precipitation, from which refrozen water $R F$ is subtracted. The latter is estimated based on the approach suggested by Oerlemans (1991) and modified by Reijmer et al. (2012). Shares of $P S$ and $P L$ in total precipitation daily sum depend on daily mean of surface air temperature $\bar{T}_{A} . M$ is determined via energy available for melting of snow/ice $E$ (from equation 4):

$$
\begin{array}{ll}
M=\max (E, 0) / L_{M} & T_{S} \geq 273.15 \mathrm{~K} \\
M=0 & T_{S}<273.15 \mathrm{~K} .
\end{array}
$$

\subsection{Algorithm of coupling}

Daily means of air surface temperature and specific humidity, used as boundary conditions for equations (1 and 2) (as well as other 'climatic variables' - surface wind speed, air pressure at the sea level and total cloudiness, which are used for parameterization of energy-exchange processes in the whole domain in figure $2 \mathrm{~b}$ ) are stored on the hard disk of the computer during one model year. Further, the data are transferred from the INMCM to EWBM-G (see figure 1) in the end of the model year. Data assimilation happens only once during model year and therefore the data exchange procedure is not computationally expensive. Further on, air surface temperature and specific humidity are remapped from the initial INMCM geographical mesh to the boundaries of a rectangular domain (figure $2 \mathrm{~b}$ ) with $20 \mathrm{~km}$ resolution and serve as boundary conditions to solve equations (1 and 2) in finite differences. Other variables are remapped not only on the boundaries, but also to the domain interior on $20 \times 20 \mathrm{~km}$ grid. Cubic splines are utilized as a remapping mean. Explicit numerical scheme is used for numerical integration of equations (1 and 2). Integration is carried out until steady state is reached for every day of the model year. According to our estimates, spline interpolation is the most computationally expensive segment of the model run. As a geometrical input, we use surface elevation field of Greenland compiled by Bamber et al. (2001).

Final results of calculations are surface temperature (upper boundary condition for ice temperature calculations), SMB (added value for calculation of ice thickness) and melt water run-off (affecting thermohaline circulation in the oceanic block of the INMCM).

\section{Simulation of SMB}

\subsection{Experimental set-up}

A 30-yr INMCM experiment simulating preindustrial conditions was run with data flow into EWBM-G as described in section 3.4. As shown in figure 5, EWBM-G satisfactorily reproduces annual and July average air surface temperatures. The field of modelled field of annual precipitation sum differs in details with respect to reconstruction of Ohmura and Reeh (1991) (figure 6). In particular, EWBM-G underestimates precipitation in the southwest of Greenland and overestimates precipitation on the eastern coast. Enhanced precipitation on the eastern coast is in line with the modelling study of Ettema et al. (2010a), though the latter predicts less precipitation in the interior area of northern Greenland.

With this climatic input, annual SMB components in the last model year were calculated using EWBM-G for slightly diverse experimental set-ups. Preliminary tests revealed that the daily air surface temperature amplitude $\tilde{T}_{A}$ in equation (6) was the main poorly constrained variable determining annual melting and run-off (Rybak et al. 2016). Rogozhina and Rau (2014) pointed that daily temperature variability was the key source of uncertainties in the calculation of ablation rate using positive degree-day method. Though we employ an alternative (energy balance) approach, we still face similar difficulties. In order to properly account for parameterization of $\tilde{T}_{A}$, we analyzed records from 21 automatic weather stations in Greenland from GC-Net (Steffen and Box 2001). It was 

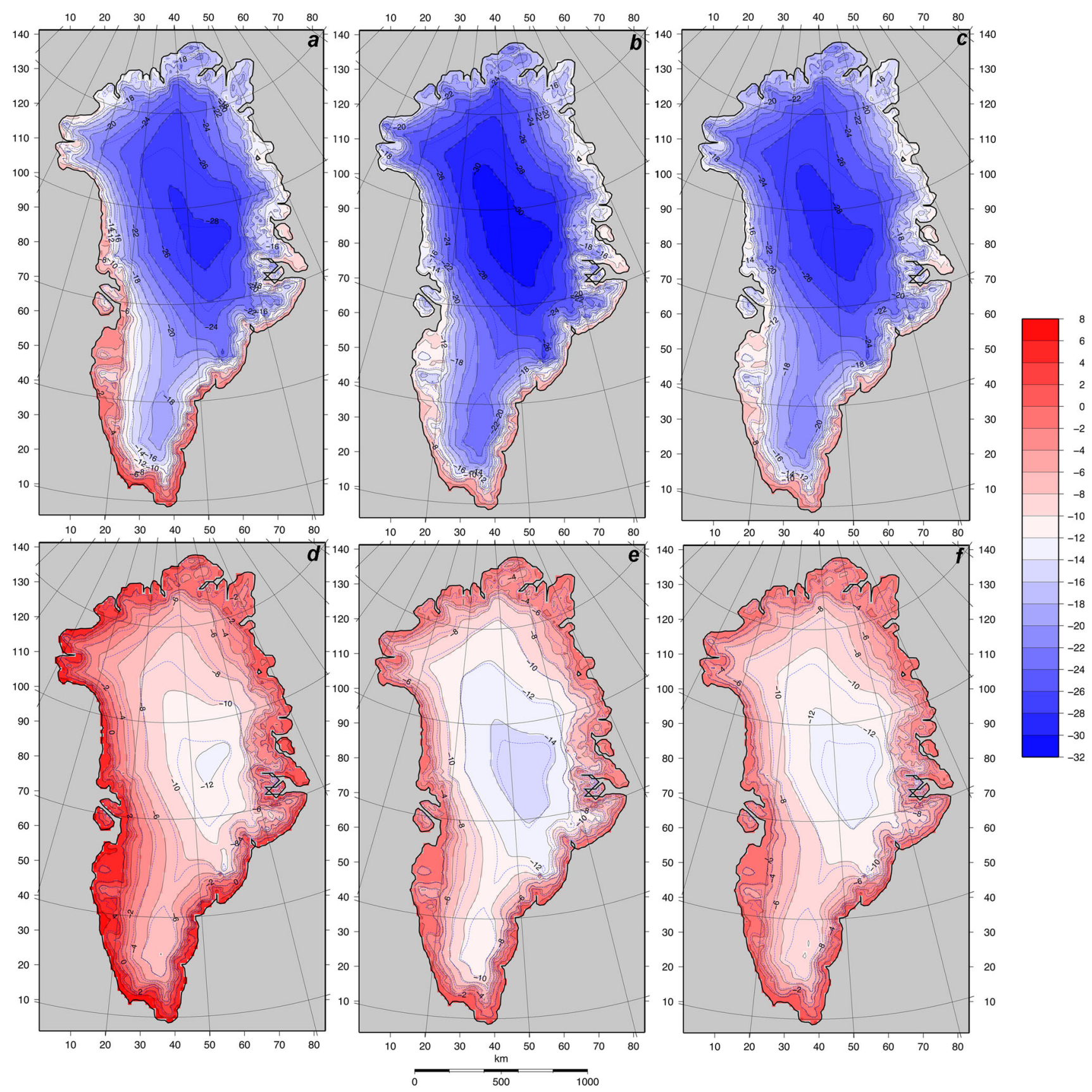

Figure 5. Annual average air surface temperature in Greenland $\left({ }^{\circ} \mathrm{C}\right)$ : $(\mathbf{a})$ modelled by the INMCM and (b) by the EWBM-G; (c) reconstruction by Fausto et al. (2009); and (d-f) same for July.

established that $\tilde{T}_{A}$ varies within the range $1-18^{\circ} \mathrm{C}$, though $\tilde{T}_{A}>12^{\circ} \mathrm{C}$ is observed mostly at surface elevation exceeding $2500 \mathrm{~m}$ (figure 7 ). There is obvious annual cycle of $\tilde{T}_{A}$ with minimum in late summer and (less visible) in the mid-winter in all elevation segments, which yields following optimum polynomial parameterization expression with linear dependency on surface elevation (Nevecherja and Rybak, submitted):

$$
\begin{aligned}
\tilde{T}_{A}= & c_{1} m+c_{2} m^{2}+c_{3} m^{3} \\
& +c_{4} m^{4}+c_{5} m^{5}+l_{0}+l_{1} z,
\end{aligned}
$$

where $m$ is the number of the day $m=1, \ldots, 365$, $z$ is the absolute height above sea level, $c_{1}-c_{5}, l_{0}$ and $l_{1}$ are the fitting coefficients.

In numerical experiments and only for the purpose of SMB calculations, air surface temperature in equation (3) was computed using monthly 

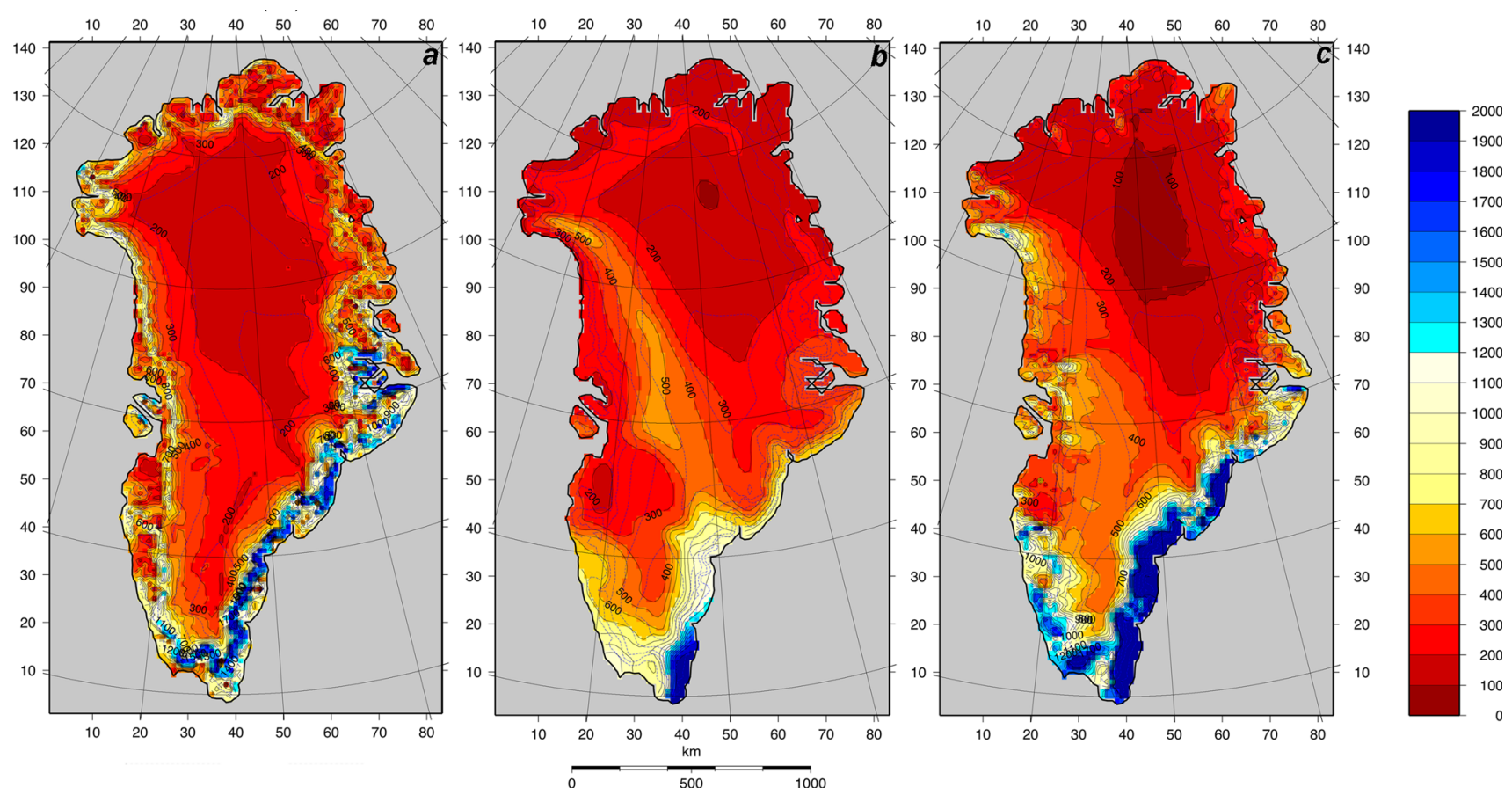

Figure 6. Annual average precipitation amounts in Greenland ( $\mathrm{mm} \mathrm{yr}^{-1}$ ) modelled by (a) the EWBM-G, (b) reconstruction by Ohmura and Reeh (1991), and (c) modelled by Ettema et al. (2010a).

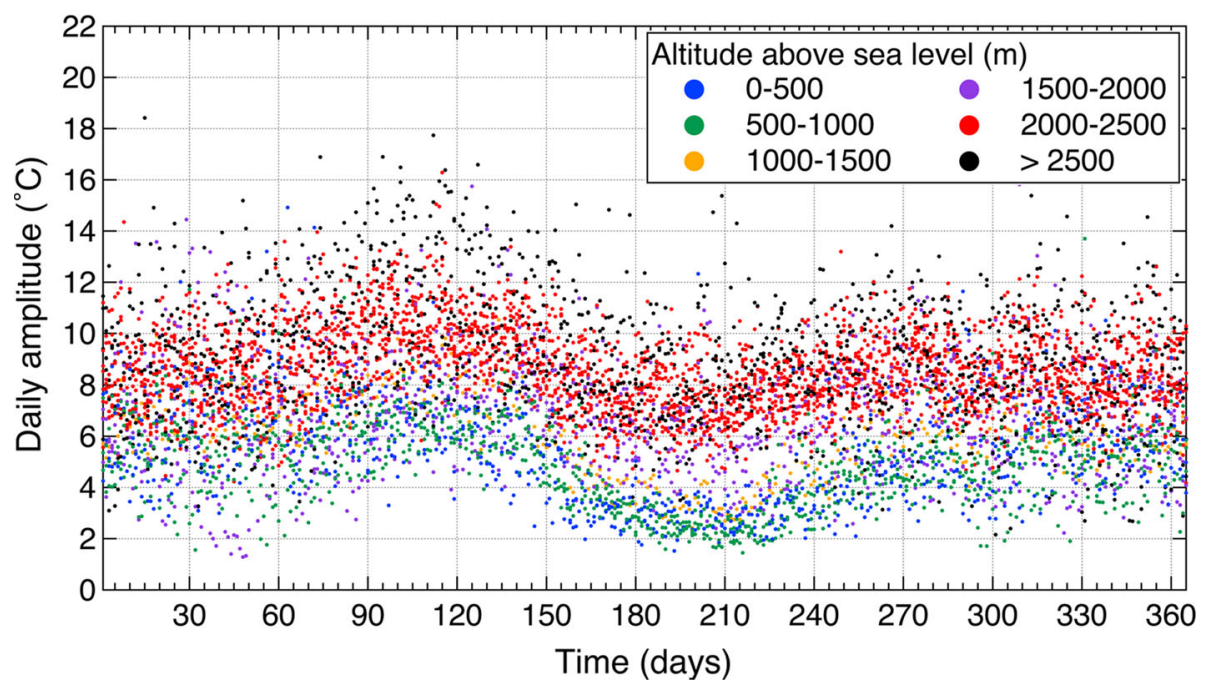

Figure 7. Average daily amplitude of surface air temperature $\left({ }^{\circ} \mathrm{C}\right)$, calculated from measurements at 21 automatic weather stations of GC-Net (Steffen and Box 2001).

lapse rates $\gamma$ established by Fausto et al. (2009) (see table 2). As mentioned above, these empirically derived 'lapse rates' at the ice surface of the ice sheet are not equivalent with the lapse rate at free atmosphere (Hanna et al. 2005). Standard deviations of daily amplitudes can be expressed as a simple linear function of surface elevation:

$$
\sigma_{\tilde{T}_{A}}=f_{0}+f_{1} z
$$

where $f_{0}=0.86$ (June), 0.63 (July), $0.77^{\circ} \mathrm{C}$ (August) and $f_{1}=1.03 \times 10^{-4}$ (June), and $2.47 \times 10^{-4}{ }^{\circ} \mathrm{C}$ $\mathrm{m}^{-1}$ (July) and $1.67 \times 10^{-4}$ (August). Typical $\sigma_{\tilde{T}_{A}}$ for elevation range $0-2500 \mathrm{~m}$ will, therefore, equal to $1.18-1.25$. Allowing possible maximum of $\tilde{T}_{A}$ exceed average by $2 \sigma_{\tilde{T}_{A}}$, we introduce in equation (9) an additional term $\Delta \tilde{T}_{A}$, which varies from 0 to $2.5^{\circ} \mathrm{C}$ with the step $0.5^{\circ} \mathrm{C}$. In total, 18 numerical experiments were performed with settings, as shown in table 3 . 
Table 2. Monthly vertical lapse rates in Greenland (mean and mean minus one standard deviation for April-October (Min) and plus one standard deviation (Max)) from Fausto et al. (2009), K $\mathrm{km}^{-1}$; '-' in the lower rows means accepted identity of Min, Max and Mean.

\begin{tabular}{lllllllllllll}
\hline Month & Jan & Feb & Mar & Apr & May & Jun & Jul & Aug & Sep & Oct & Nov & Dec \\
\hline Mean & -7.9 & -8.9 & -7.9 & -7.3 & -5.9 & -4.7 & -4.6 & -5.7 & -6.9 & -7.3 & -6.5 & -7.6 \\
Min & - & - & - & -5.0 & -3.2 & -4.1 & -4.0 & -5.1 & -4.7 & - & - & - \\
Max & - & - & - & -9.6 & -8.6 & -5.3 & -5.2 & -6.5 & -9.1 & - & - & - \\
\hline
\end{tabular}

Table 3. Experimental set-up.

\begin{tabular}{lcc}
\hline $\begin{array}{l}\text { Experiment } \\
\text { no. }\end{array}$ & $\begin{array}{c}\text { Vertical lapse } \\
\text { rate from table } 2\end{array}$ & $\begin{array}{c}\text { Additional } \\
\text { term } \Delta \tilde{T}_{A},{ }^{\circ} \mathrm{C}\end{array}$ \\
\hline 1 & Mean & 0 \\
2 & Mean & +0.5 \\
3 & Mean & +1.0 \\
4 & Mean & +1.5 \\
5 & Mean & +2.0 \\
6 & Mean & +2.5 \\
7 & Min & 0 \\
8 & Min & +0.5 \\
9 & Min & +1.0 \\
10 & Min & +1.5 \\
11 & Min & +2.0 \\
12 & Min & +2.5 \\
13 & Max & 0 \\
14 & Max & +0.5 \\
15 & Max & +1.0 \\
16 & Max & +1.5 \\
17 & Max & +2.0 \\
18 & Max & +2.5 \\
\hline
\end{tabular}

\subsection{Results and discussion}

Results of experiments 1-18 were collated with the results of similar studies (table 4). It is notable that model mass balance components are highly variable. Slight differences in GrIS geometries and in periods of simulations are partially responsible for variance from model to model. But differences are much higher than that. For instance, average annual melting calculated in RACMO2/GR for 1958-2007 is 70\% lower than in MAR5 and $60 \%$ higher than in POLAR MM5 for the same period. Same variance is obvious in refrozen water and in run-off estimates. At the same time, difference in solid precipitation for these three models is approximately 20\%. In other words, variation in surface mass input to GrISM is not dramatically large. The same applies for the EWBM-G with total solid precipitation 577-611 Gt $\mathrm{yr}^{-1}$. Since liquid precipitation sum is only $5-8 \%$ of solid precipitation and sublimation is even lower, scatter between models in annual accumulation rate is also about $20 \%$. It reflects differences in source of precipitation (reanalysis, 'parent' climate models). But diverse results in discharge part of SMB are totally attributed to differences in general modelling concepts, approaches and numerical methods. Due to the lack of appropriate observational data for constraining results of simulations, it is not possible to objectively judge, which model is better than the others (figure 8).

We have already focused on high dependency of modelled melting rate on imposed $\tilde{T}_{A}$ (Rybak et al. 2016). This result is supported by findings of Rogozhina and Rau (2014). In our 18 experiments, we obtained linear dependency of run-off on SMB (figure 8). This result is, in general, in line with other modelling exercises, though the latter are not numerous. This result is not surprising because all models, at the end, employ approaches based on the same basic physical principles.

One of the possible constraints (but by no means a universal one) is the satellite-measured extent of surface melting area and number of days with melting events (Abdalati 2008). Melting area varies essentially from year to year (figure $9 \mathrm{a}$ ). We have chosen the years of minimum and of maximum areas (figure $9 \mathrm{~b}$ ) for qualitative comparison with our modelling results. Since the patterns of observed and modelled melting do not coincide exactly, quantitative comparison also will not be precise. Modelled melting areas (figure 10) correspond to extreme experimental setup with zero additional term to daily amplitude $\left(\tilde{T}_{A}\right.$ in equation 6$)$ on the left panels and maximum $\left(+2.5^{\circ} \mathrm{C}\right)$ term on the right. Experimental results in the upper row of figure 10 were obtained assuming average monthly lapse rates. Minimum lapse rates (average minus one standard deviation) were used for experiments in the middle row. Maximum lapse rates (average plus one standard deviation) were assumed for the experiments in the 


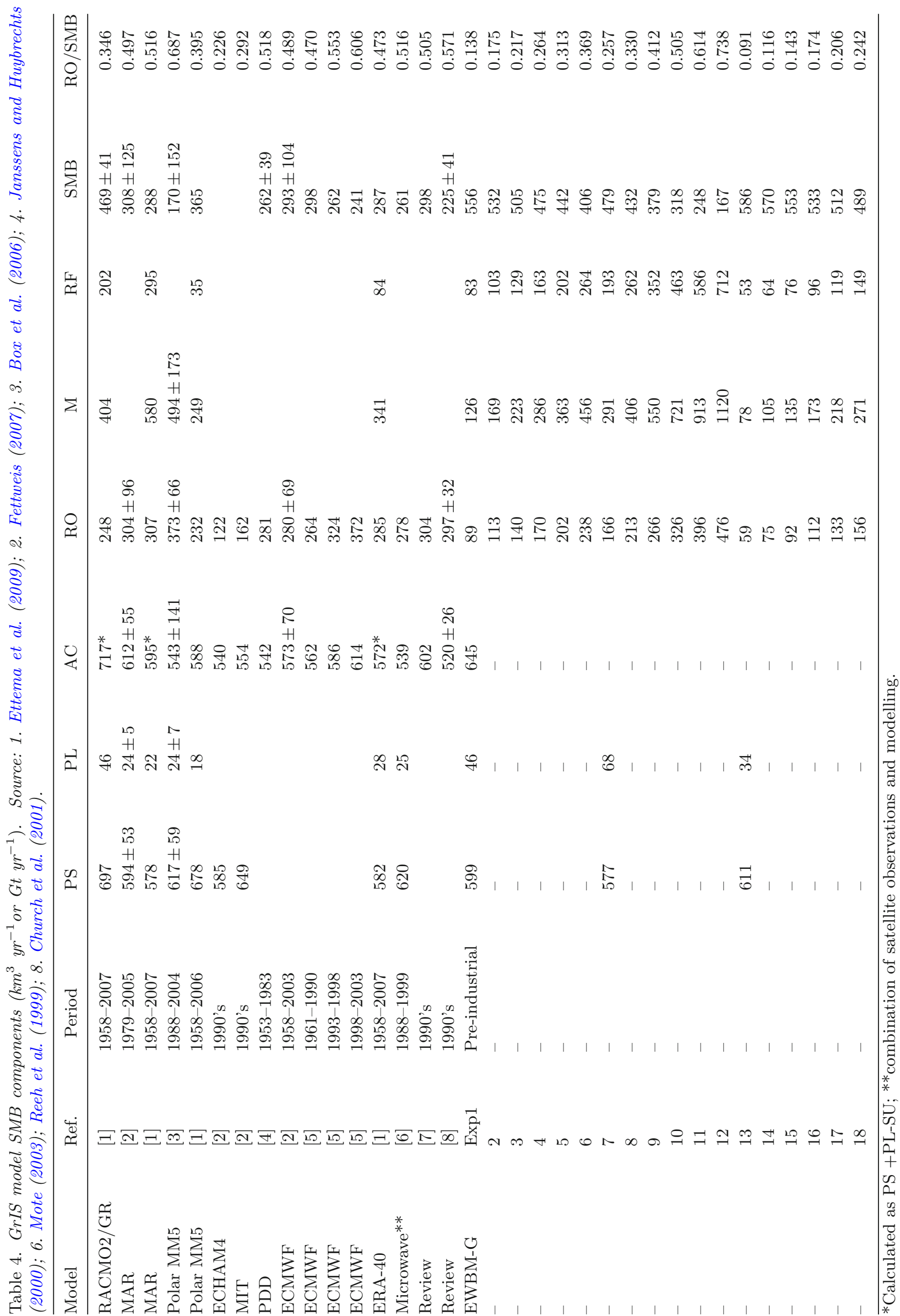




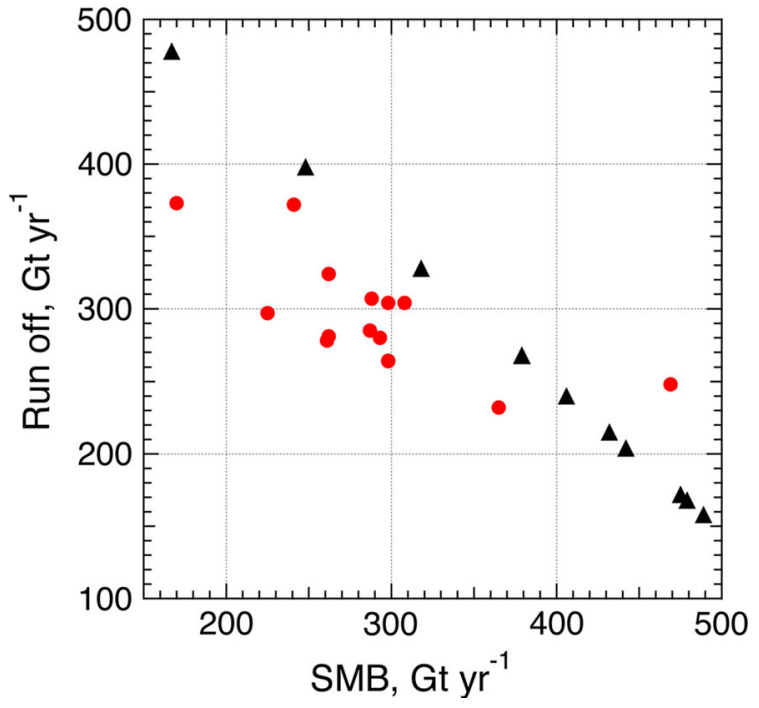

Figure 8. Modelled run-off plotted against SMB (both in Gt $\left.\mathrm{yr}^{-1}\right)$. Red circles denote model results from table 4 except those contained with the EWBM-G, black triangles - modelled by the EWBM-G. Lower (SMB) axis is cut off at 500 Gt $\mathrm{yr}^{-1}$. lower row. Experimental set-ups are summarized in table 3.

Obviously, exp1 and exp13 provide melting areas, which are the most close to the observed 1992 satellite measured area (minimum melting area in the record). The apparent difference is the lack of observed melting in the northwest of Greenland and in the mountainous region in the east compared to the modelled distribution. Maximum observed area (in 2005) is better reproduced in exp6. Exp7 already overestimated maximum observed melting area for the period 1979-2007. But the modelled melting area looks realistic in case of extreme warm conditions, for instance, like in 2012, when melting area for the short period of time covered $97 \%$ of the GrIS (Nghiem et al. 2012). In general, modelled melting area covers the whole GrIS in experiments 8-12. A tendency of gradual melting area growth was traced by Tedesco et al. (2013) for the whole period after 2007. So the
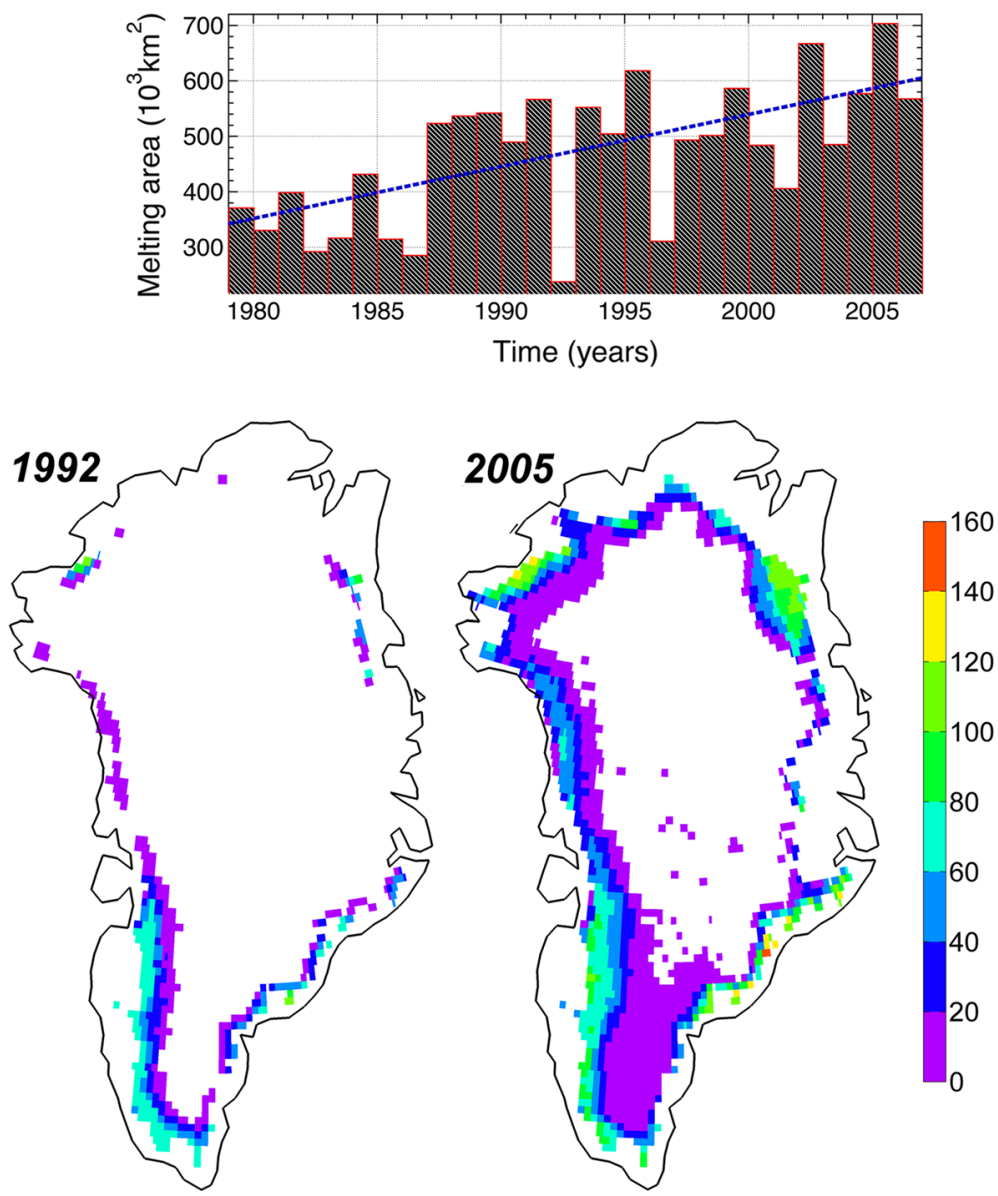

Figure 9. Number of days with melting events in 1992 and 2005 (Abdalati 2008). 

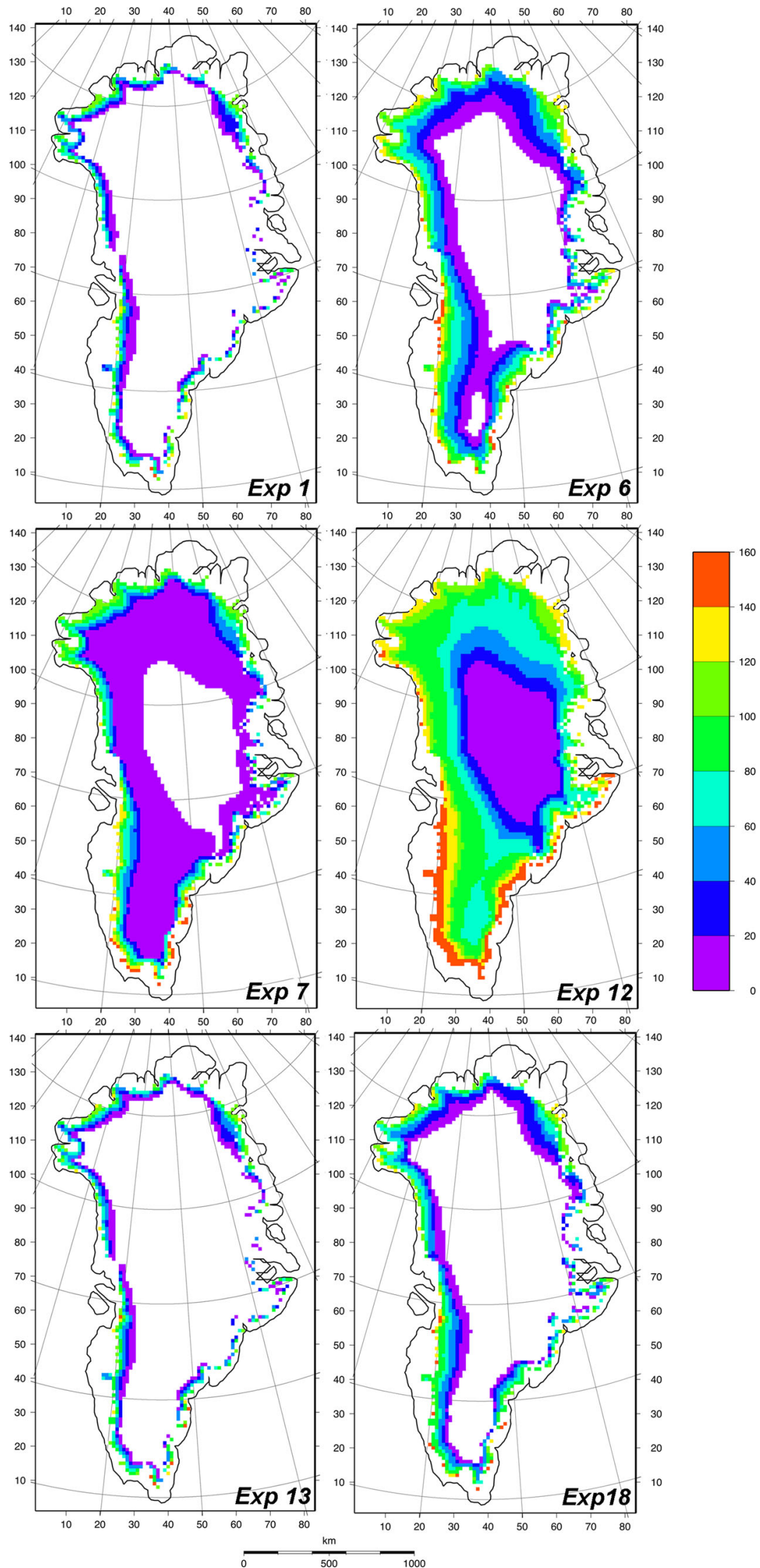

Figure 10. Number of days with melting events in the numerical experiments performed on the EWBM-G (see text for explanation). 
experimental results strongly depend on setting of the key tuned parameter $\tilde{T}_{A}$ in equation (6). Since the boundary conditions for our numerical experiments are imposed for conventional pre-industrial climate, spread of the melting area on the whole ice sheet seems hardly possible. Therefore, application of minimum 'lapse rates' from table 2 leads to apparent overestimation of melting and runoff. At the same time, using maximum lapse rates (exp13-exp18) leads to underestimation of the above-mentioned SMB components.

Comparing results of experiments 7 and 1 (figure 11) reveals the role of refreezing in the formation of SMB. Melting amount in exp6 is more than twice higher than in exp1, but the mass balance in exp7 is only $14 \%$ lower than in exp1. Mass balance in both experiments (figure 11c, g) are quite alike. It is explained by outrunning refreezing (figure 11b, f). Similar relations between melting amounts and mass balances are kept when comparing exp7 and exp13. Therefore, within the frameworks of our approach, simulated mass balance is rather a conservative feature, which is less sensitive to setting of $\tilde{T}_{A}$ than ablation and run-off. The latter is less sensitive to surface temperature compared to melting, but still much more sensitive compared to SMB. Relatively high sensitivity of the run-off to parameterization scheme may complicate realistic quantification of GrIS contribution to sea level rise in warming climate. This is well illustrated by a $30 \%$ scatter of run-off averages estimated by four models for the time period 19582006/2007 (RACMO2/GR, Polar MM5, ERA40,see table 4). Run-off to accumulation ratio for these four models is even higher - approximately $50 \%$. In our experiments $1-2$ and $13-17$, the $R O / A C C$ ratio is substantially lower than predicted by all other models.

Rest of the experiments predict the ratios, which fit in the range of other models' predictions. From the point of view of this intercomparison, maximum 'lapse rates' should be negated as they lead to underestimation of melting and run-off. The same applies to free atmosphere lapse rate, which is closer to maximum surface lapse rates or even exceeds them. The only exception is exp18. In this case, adding an extra $+2.5^{\circ} \mathrm{C}$ term to $\tilde{T}_{A}$ compensates high lapse rate value. This is really at the limit of observed statistics. Using of minimum 'lapse rates' (except perhaps in exp7) is also questionable, because in exp8-12 melting area is extremely large for conventional pre-industrial boundary conditions. As a result of this qualitative
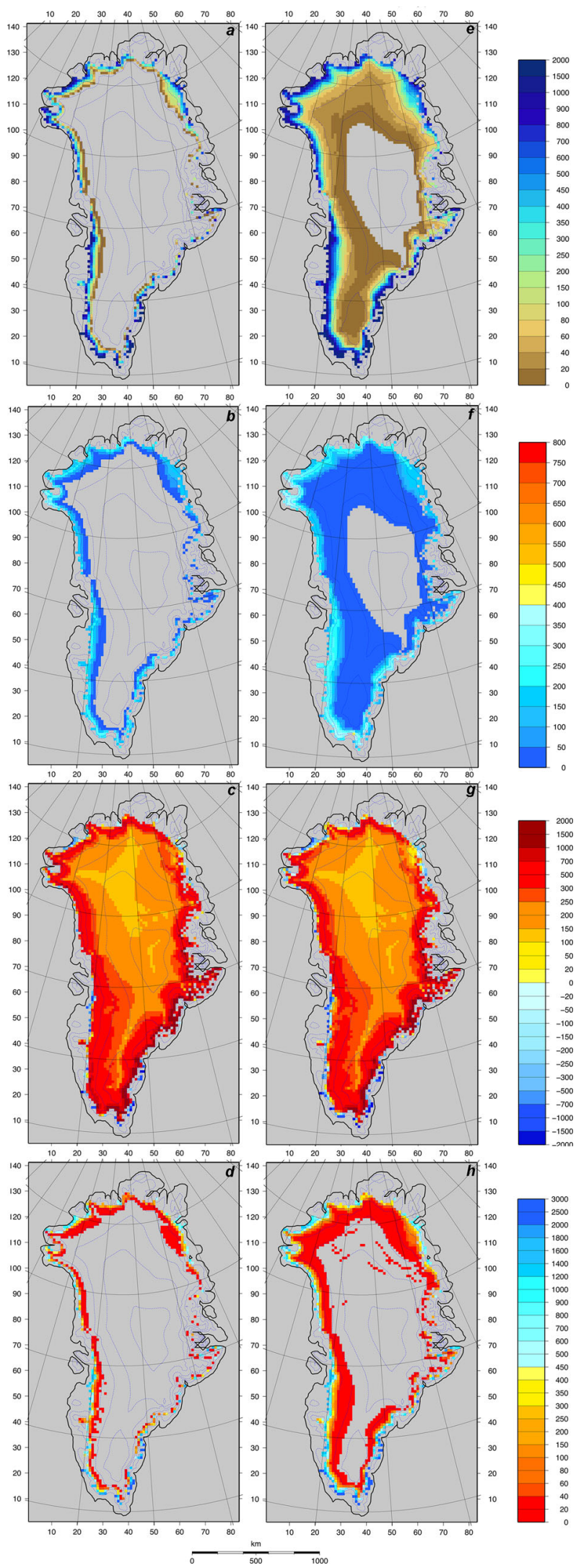

Figure 11. Modelled on the EWBM-G annual meanings of SMB and SMB components on the surface of GrIS (mm $\mathrm{yr}^{-1}$ ), (a) ablation rate, (b) refrozen ice, (c) run-off, (d) $\mathrm{SMB}$, in numerical experiments 1 (left panels) and 7 (right panels). 
overview, we can point to exp3-7 as the best fitting to the range of predictions by other models.

\section{Summary and outlook}

The focus of the current study is the methodological aspects of the coupling of GrISM and AISM to an AOGCM. Fundamental differences between the Greenland and Antarctic ice sheets dictate different approaches for coupling. Surface melting plays a negligible role in Antarctica (except Antarctic peninsula and ice shelves). Besides, there is stronger similarity between observed and INMCMgenerated temperature fields and precipitation patterns in Antarctica compared to Greenland. Therefore, it was much more convenient to apply direct transfer of the INMCM climatic output to the AISM. This transfer requires, of course, application of resampling and interpolation procedures to remap climatic output from the grid $5^{\circ} \times 4^{\circ}$ into the grid $20 \times 20 \mathrm{~km}$, which is a standard input format in ice sheet models. Since model annual precipitation sum averaged over the continent is as twice as higher than the reconstructed one, we impose model-based anomalies on the reconstruction; thus emulating year-to-year changes in precipitation. In our approach, accumulation simply equals to precipitation. In future, we plan to apply more sophisticated approach and to implement for Antarctica a simple buffer model similar to that used for Greenland.

The latter, an energy- and water-balance model (EWBM-G), was developed for the purpose of dynamical coupling of the GrISM to the climate model. Testing of EWBM-G for pre-industrial climatic conditions reconstructed by the climate model INMCM and comparison with observations and reconstructed data allows to conclude that the EWBM-G in general satisfactorily reproduces fields of annual average air surface temperature and annual precipitation. The latter are the key variables for calculation of surface mass balance in the model of the GrIS dynamics. Simplicity of the EWBM-G and low computational demand makes it very effective for application as an interface for data exchange between the climate model INMCM and the ice sheet model. Modelled SMB and run-off are rather sensitive to parameterization of amplitudes of air surface temperature. Lack of reliable constraints is really a problem. Sensitivity analysis and model intercomparison enabled to establish the suitable range of parameters. The next step in developing of a coupled INMCM-EWBM-GrISM system is to use surface run-off and basal melting water fluxes as an input to the oceanic block to force thermohaline circulation.

Full coupling of the GrISM and the AISM to the INMCM finalizes elaboration of an Earth system model. In forthcoming papers, we plan to focus on transient runs of the model. The coupling procedure developed in this study is applicable mainly for simulation of rather moderate climatic change, for instance, future change under the influence of growth of greenhouse gases' concentration. Simulating of palaeoclimates will require certain revision of the coupling methodology, because some key model parameters (i.e, daily amplitudes of surface air temperatures (in case of Greenland) or climatic precipitation fields (in case of Antarctica)) are basically unknown.

\section{Acknowledgements}

This paper is dedicated to the memory of Julián Adem (1924-2015, Universidad Nacional Autónoma de México, UNAM), who brilliantly proved that simplified modelling methods could be successfully applied in climatological studies. Research was carried out in the Institute of Numerical Mathematics of RAS (Moscow) and was supported by the Russian Science Foundation (Project No. 1427-00126 'Study of the Earth's climate with the next generation Earth system model'). Authors appreciate comments of anonymous reviewers, which helped to essentially improving earlier version of the paper.

\section{References}

Abdalati W 2008 Greenland ice sheet melt characteristics derived from passive microwave data; Boulder, Colorado USA: National Snow and Ice Data Center, https://doi. org/10.5067/NON9395MQ9TK.

Adem J 1964 On the physical basis for the numerical prediction of monthly and seasonal temperatures in the troposphere-ocean-continent system; Mon. Wea. Rev. 92 91-103.

Adem J 1979 Low resolution thermodynamic grid models; Dyn. Atmos. Ocean. 3 433-451.

Adem J 1981a Numerical experiments on ice age climates; Clim. Dyn. 3 155-171.

Adem J 1981b Numerical simulation of the annual cycle of climate during the ice ages; J. Geophys. Res. 86 1201512034 .

Bamber J L, Ekholm S and Krabill W B 2001 A new, high resolution digital elevation model of Greenland fully validated with airborne laser altimeter data; J. Geophys. Res. 106 6733-6745. 
Barbi D, Lohmann G, Grosfeld K and Thoma M 2014 Ice sheet dynamics within an earth system model: Downscaling, coupling and first results; Geosci. Model Dev. 7 2003-2013.

Berger A, Loutre M-F and Gallée H 1998 Sensitivity of the LLN climate model to the astronomical and $\mathrm{CO}_{2}$ forcings over the last $200 \mathrm{ky}$; Clim. Dyn. 14 615-629.

Box J E, Bromwich D H, Venhuis B A, Bai L-S, Stroeve J C, Rogers J C, Steffen K, Haran T and Wang S-H 2006 Greenland ice sheet surface mass balance variability (1988-2004) from calibrated Polar MM5 output; J. Clim. 19 2783-2800.

Budyko M I 1969 The effect of solar radiation variations on the climate of the earth; Tellus 21 611-619.

Cazenave A, Remy F, Dominh K and Douville H 2000 Global ocean mass variation, continental hydrology and the mass balance of Antarctica ice sheet at seasonal time scale; Geophys. Res. Lett. 27 3755-3758.

Church J A, Gregory J M, Huybrechts P, Kuhn M, Lambeck C, Nhuan M T, Qin D and Woodworth P L 2001 Changes in sea level; In: Climate Change 2001: The Scientific Basis - Contribution of Working Group I to the Third Assessment Report of the Intergovernmental Panel on Climate Change (eds) Houghton J T et al., Cambridge University Press, New York, pp. 639-694.

Dobrovolski S G and Rybak O O 1992 Incorporation of hydrologic cycle elements into the dynamic-stochastic climate model; GeoJournal 27 247-254.

Ettema J, van den Broeke M R, van Meijgaard E, van de Berg W J, Bamber J L, Box J E and Bales R C 2009 High surface mass balance of the Greenland ice sheet revealed by high-resolution climate modelling; Geophys. Res. Lett. 36 L12501, https://doi.org/10.1029/2009GL038110.

Ettema J, van den Broeke M R, van Meijgaard E, van de Berg W J, Box J E and Steffen K 2010a Climate of the Greenland ice sheet using a high-resolution climate model - Part 1: Evaluation; The Cryosphere 4 511-527.

Ettema J, van den Broeke M R, van Meijgaard E and van de Berg W J 2010b Climate of the Greenland ice sheet using a high-resolution climate model - Part 2: Near surface climate and energy balance; The Cryosphere 4 529-544.

Fanning A F and Weaver A J 1996 An atmospheric energymoisture balance model: Climatology, interpentadal climate change, and coupling to an ocean general circulation model; J. Geophys. Res. 101(D10) 15,111-15,128.

Fausto R S, Ahlstrøm A P, Van A D, Bøggild C E and Johnsen S J 2009 A new present-day temperature parameterization for Greenland; J. Glaciol. 55 95-105.

Fettweis X 2007 Reconstruction of the 1979-2006 Greenland ice sheet surface mass balance using the regional climate model MAR; The Cryosphere 1 21-40.

Fyke J G, Weaver A J, Pollard D, Eby M, Carter L and Mackintosh A 2011 A new coupled ice sheet/climate model: Description and sensitivity to model physics under Eemian, Last Glacial Maximum, late Holocene and modern climate conditions; Geosci. Model Dev. 4 117-136.

Gallée H, Van Ypersele J P, Fichefet T, Marsiat I, Tricot C and Berger A 1992 Simulation of the Last Glacial cycle by a coupled, sectorial averaged climate-ice sheet model: 2. Response to insolation and $\mathrm{CO}_{2}$ variations; J. Geophys. Res. 97 15,713-15,740.
Gates W L 1976 The numerical simulation of ice-age climate with a global general circulation model; J. Atmos. Sci. 33 1844-1873.

Giovinetto M B and Zwally H J 2000 Spatial distribution of net surface accumulation on the Antarctic ice sheet; Ann. Glaciol. 31 171-178.

Hanna E, Huybrechts P, Janssens I, Cappelen J, Steffen K and Stephens A 2005 Runoff and mass balance of the Greenland ice sheet: 1958-2003; J. Geophys. Res. 110 D13108, https://doi.org/10.1029/2004JD005641.

Huybrechts P 1992 The Antarctic ice sheet and environmental change; Berichte zur Polarforschung 99 241p.

Huybrechts P 1993 Glaciological modelling of the Late Cenozoic East Antarctic ice sheet: Stability or dynamism? Geografiska Annaler 75 221-238.

Huybrechts P 2002 Sea-level changes at the LGM from icedynamic reconstructions of the Greenland and Antarctic ice sheets during the glacial cycles; Quat. Sci. Rev. 21 203-231.

Huybrechts P and de Wolde J 1999 The dynamic response of the Greenland and Antarctic ice sheets to multiplecentury climatic warming; J. Clim. 12 2169-2188.

Huybrechts P, Steinhage D, Wilhelms F and Bamber J 2000 Balance velocities and measured properties of the Antarctic ice sheet from a new compilation of gridded data for modelling; Ann Glaciol. 30 52-60.

Janssens I and Huybrechts P 2000 The treatment of meltwater retention in mass-balance parameterizations of the Greenland ice sheet; Ann. Glaciol. 31 133-140.

Jenssen D 1977 A three-dimensional ice sheet model; J. Glaciol. 18 373-389.

Lenaerts J T M, van den Broeke M R, van de Berg W J, van Mejgaard E and Kuipers Munneke P 2012 A new, highresolution surface mass balance map of Antarctica (19792010) based on regional atmospheric climate modelling; Geophys. Res. Lett. 39 L04501, https://doi.org/10.1029/ 2011GL050713.

Mahaffy M W 1976 A three-dimensional numerical model of ice sheets: Tests on the Barnes Ice Cap, northwest territories; J. Geophys. Res. 80 1059-1066.

Mote T L 2003 Estimation of runoff rates, mass balance, and elevation changes on the Greenland ice sheet from passive microwave observations; J. Geophys. Res. 108 4056, https://doi.org/10.1029/2001JD002032.

Nghiem S V, Hall D K, Mote T L, Tedesco M, Albert M R, Keegan K, Shuman C A, DiGirolamo N E and Neuman G 2012 The extreme melt across the Greenland ice sheet in 2012; Geophys. Res. Lett. 39 L20502, https://doi.org/ 10.1029/2012GL053611.

North G R, Cahalan R F and Coakley J A 1981 Energy balance climate models; Rev. Geophys. Space Phys. 19 91-121.

Oerlemans J 1991 The mass balance of the Greenland ice sheet: Sensitivity to climate change as revealed by energybalance modelling; The Holocene 1 40-49.

Ohmura A and Reeh N 1991 New precipitation and accumulation map for Greenland; J. Glaciol. 37 140-148.

Petoukhov V, Ganopolski A, Brovkin V, Claussen M, Eliseev A, Kubatzki C and Rahmstorf S 2000 CLIMBER-2: A climate system model of intermediate complexity. Part I: Model description and performance for present climate; Clim. Dyn. 16 1-17. 
Reeh N, Mayer C, Miller H, Thomson H H and Weidick A 1999 Present and past climate control on Fjord glaciations in Greenland: Implications for IRD-deposition in the sea; Geophys. Res. Lett. 26 1039-1042.

Reijmer C H, van den Broeke M R, Fettweis X, Ettema J and Stap L B 2012 Refreezing on the Greenland ice sheet: A comparison of parameterizations; The Cryosphere 6 743-762.

Robinson A, Calov R and Ganopolski A 2010 An efficient regional energy-moisture balance model for simulation of the Greenland ice sheet response to climate change; The Cryosphere 4 129-144.

Roche D M, Dumas C, Bügelmayer M, Charbit S and Ritz C 2014 Adding a dynamical cryosphere to $i$ LOVECLIM (version 1.0): Coupling with the GRISLI ice-sheet model; Geosci. Model Dev. 7 1377-1394.

Rogozhina I and Rau D 2014 Vital role of daily temperature variability in surface mass balance parameterizations of the Greenland ice sheet; The Cryosphere 8 575-585.

Rybak O O 1992 On the application of a dynamic-stochastic climate model to the simulation of the oceanic upper layer thermal variability; Atmósfera 5 181-192.

Rybak O O and Volodin E M 2015 Applying the energy and water balance model for incorporation of the cryospheric component into a climatic model. Part I. Description of the model and computed climatic field of air surface temperature and precipitation rate; Russian Meteorol. Hydrol. 40(11) 33-45, https://doi.org/10.3103/ S1068373915110035.

Rybak O O, Volodin E M, Nevecherja A P and Morozova P A 2016 Applying the energy- and water balance model for incorporation of the cryospheric component into a climatic model. Part I. Description of the model and computed climatic field of air surface temperature and precipitation rate; Russian Meteorol. Hydrol. 41(6) 379-387, https:// doi.org/10.3103/S1068373916060017.

Steffen K and Box J 2001 Surface climatology of the Greenland ice sheet: Greenland climate network 1995-1999; J. Geophys. Res. 106 33,951-33,964.

Tedesco M, Fettweis X, Mote T, Wahr J, Alexander P, Box J E and Wouters B 2013 Evidence and analysis of 2012 Greenland records from spaceborne observations, a regional climate model and reanalysis data; The Cryosphere 7 615-630.

Thoma M R, Gerdes R, Greatbatch R J and Ding H 2015 Partially coupled spin-up of the MPI-ESM: Implementation and first results; Geosci. Model Dev. 8 51-68.

van de Berg W J, van den Broeke M R, Rijmer C $\mathrm{H}$ and van Meijgaard E 2005 Characteristics of the Antarctic surface mass balance, 1958-2002, using a regional climate model; Ann. Glaciol. 41 97-104.

Vizcaíno M, Mikolajevicz U, Jungclaus J and Schurgers G 2008 Long-term ice sheet-climate interactions under antropogenic green-house forcing simulated with a complex Earth system Model; Clim. Dyn. 31 665-690.

Vizcaíno M, Mikolajevicz U, Jungclaus J and Schurgers G 2010 Climate modification by future ice sheet changes and consequences for ice sheet mass balance; Clim. Dyn. 34 301-324.

Volodin E M 2013 The mechanism of multidecadal variability in the Arctic and North Atlantic in climate model INMCM4; Environ. Res. Lett., https://doi.org/10.1088/ 1748-9326/8/3/035038.

Volodin E M 2014 Possible reasons for low climate-model sensitivity to increased carbon dioxide concentrations; Izvestiya Atmos. Ocean Phys. 50 350-355, https://doi. org/10.1134/S0001433814040239.

Volodin E M 2015 Influence of methane sources in Northern Hemisphere high latitudes on the interhemispheric asymmetry of its atmospheric concentration and climate; Izvestiya Atmos. Ocean Phys. 51 251-258, https://doi. org/10.1134/S0001433815030123.

Volodin E M and Kostrykin S V 2016 The aerosol module in the INM RAS climate model; Russian Meteorol. Hydrol. 41 519-528, https://doi.org/10.3103/ S106837391608001X.

Volodin E M, Dianskii N A and Gusev A V 2010 Simulating present-day climate with the INMCM4.0 coupled model of the atmospheric and ocean general circulations; Izvestiya Atmos. Ocean Phys. 46 414-431, https://doi. org/10.1134/S0001433811050124.

Volodin E M, Diansky N A and Gusev A V 2013 Simulation and prediction of climate changes in the 19th to 21st centuries with the Institute of Numerical Mathematics, Russian Academy of Sciences, model of the Earth's climate system; Izvestiya Atmos. Ocean Phys. 49 347-366, https://doi.org/10.1134/S0001433813040105.

Volodin E M, Galin V Ya, Gritsun A S, Gusev A V, Diansky N A, Dymnikov V P, Ibrayev R A, Kalmykov V V, Kostrykin S V, Kuliamin D V, Lykossov V N, Mortikov E V, Rybak O O, Tolstykh M A, Fadeev R Yu, Chernov I A, Shashkin V V and Iakovlev N G 2016 Mathematical modelling of the Earth's system (ed.) Iakovlev N G, Moscow, Max Press, 328p (in Russian).

Yurova A Yu and Volodin E M 2011 Coupled simulation of climate and vegetation dynamics; Izvestiya Atmos. Ocean Phys. 47 531-539, https://doi.org/10. 1134/S0001433811050124.

Corresponding editor: A K SAHAI 